\title{
Negotiating Tasks in EFL Classrooms
}

\author{
Luu Trong Tuan \\ National University of Ho Chi Minh City, Vietnam \\ Email: luutrongtuan@vnn.vn
}

\begin{abstract}
This paper sought to examine whether task negotiation - a process in which the teacher and students involve in a joint enterprise, discussing with each other what tasks to be done and how-could accommodate students' learning needs and increase their learning effectiveness. 77 first-year students from the two EFL classes, one treated as the experimental group (EG) and the other as the control group (CG), at the Faculty of English Linguistics of Hung Vuong University were invited to participate in the study, whose findings substantiated the benefits of task negotiation as an effective activity to enhance learners' motivation, involvement, and achievement, as well as to build a close bonding between teachers and learners.
\end{abstract}

Index Terms - task negotiation, learning needs, learning effectiveness, motivation, English as a foreign language (EFL) learners

\section{INTRODUCTION}

Since the 1960s, learner-centredness has become a topic of widespread discussion in the language teaching literature. Much effort has gone into finding means of making language teaching more responsive to learners' needs, characteristics and expectations, encouraging their active involvement in their own learning and educating them to become independent and ongoing learners. This preoccupation of learner-centredness is evident in the emergence of a number of trends in the professional literature such as humanistic language teaching, communicative language teaching, learning strategy research, individualisation, learner autonomy and syllabus negotiation (Tudor, 1996). The final notion represents one of the most significant innovations in recent years which highlight the importance of learner independence, collaborative learning and shared decision-making (Breen \& Littlejohn, 2000). In negotiative approaches, teacher and learners discuss with each other to decide what to learn and how to learn it. Proponents of this development believe that the syllabus which emerges from the negotiating process will be more flexible and relevant to learners' needs and thus more motivating and will allow learners to play a more informed and self-directive role in their learning (Bloor \& Bloor, 1988; Nunan, 1988; Boomer et al., 1992; Nunan, 1992, 1999; Tudor, 1996; Breen \& Littlejohn, 2000). The fact that there is a growing number of teachers' accounts of successful negotiated work in a wide range of educational settings (in Western and Eastern cultures, in state and private institutions, in small and large classes, with students of different age ranges and levels) demonstrate the feasibility of negotiation in diverse contexts (Boomer et al., 1992; Breen \& Littlejohn, 2000; Huang, 2006). This indicates the potential of this approach in the realm of language teaching and learning.

In Vietnam, learner-centredness has become one of the buzzwords in the language teaching circle over recent years. Ways to tailor the teaching to learners' needs and encourage learners to become active participants have been the focus of numerous workshops and studies. There have, however, been few research projects on negotiation as a learnercentred approach to language teaching although interest in this development is high in the professional literature. It was this fact that motivated the researcher in the first place to carry out the study in order to investigate how negotiation works in the Vietnamese context.

Another inspiration of the study is the concern over Vietnamese learners' verbal communicative competence and the growing interest in communicative language teaching in Vietnam in recent years. For a long period of time, the language teaching in Vietnam has been dominated by grammar - translation methods, which results in the often heard complaint that Vietnamese learners are good at grammar, reading and writing but cannot conduct a short conversation well. With the development of economy, Vietnam has become a popular destination for foreign tourists and investors; mastering spoken English has, therefore, become a must for learners of English. This demand leads to the shift of focus towards the aural/oral skills and communicative approaches to language teaching. This drove the researcher to conduct research on syllabus negotiation, a development which emerged from the communicative language teaching movement and has been vigorously upheld by a growing number of writers. According to Breen (2001) "collaborative decisionmaking about different aspects of the teaching - learning process in the classroom [...] involves learners in authentic opportunities to use and develop their knowledge and capabilities" (p. 154). While engaging them in responsible decisions about their work, syllabus negotiation generates meaningful interaction among the participants in the classroom and thus contributes to learners' language development.

Above are the primary factors that led to the implementation of the study on syllabus negotiation in EFL classes. The research just focuses on the task level of the syllabus, however. One obvious reason is the existence of a pre-determined syllabus in the context of the study. The other is the increasing recognition of the importance of tasks in syllabus design 
ever since the emergence of task-based learning. Research on second language acquisition area during the 1980s suggested that learners' interaction and, through it, negotiation for meaning during task performance could facilitate their acquisition of linguistic knowledge and its social use. It is, therefore, proposed that task should be the key unit in the syllabus and teachers should provide appropriate tasks that can generate rich and meaningful interaction which will be facilitative of language acquisition. In addition, some writers have highlighted a connection between learnercentredness and learning tasks in the classroom (Wright, 1987; Nunan, 1989). Nunan (1989), for instance, suggests learner role and teacher role as two components of a task and points out the need to involve learners in task design and selection. Given the significant implications for language acquisition and learner-centredness of tasks in classrooms, the researcher found it justified in undertaking negotiation between teacher and learners at the level of tasks.

The research focuses on task negotiation, namely the teacher discussing with students in order to reach agreement with respect to what tasks are going to be done and how. Two questions were formulated to guide the research:

(1) What are the impact of task negotiation on the teaching and learning English?

(2) What are the students' reactions towards the application of task negotiation to English teaching and learning?

\section{LITERATURE REVIEW}

\section{A. Negotiation}

1. Definitions of 'negotiation'

As can be noticed from the historical account of the formative influences of the idea of negotiated decision-making, the term "negotiation" refers to different things in the language teaching world. Breen and Littlejohn (2000) distinguish three types of negotiation: personal negotiation, interactive negotiation and procedural negotiation.

Personal negotiation refers to the complex mental process that occurs when we interpret what we read or hear or when we try to express what we mean in writing or speaking (Breen \& Littlejohn, 2000). An example of this kind of negotiation is that one poem can be interpreted differently by different people owing to their different previous knowledge and experience. It can be understood differently even by the same person the second time (s)he reads it. This kind of negotiation is inevitable whenever we use language for interpreting or expressing meaning.

Interactive negotiation or negotiation of meaning is "the interactional work done by speakers and listeners to ensure that they have a common understanding of the ongoing meanings in a discourse" (Nunan, 1999: 311). This notion, as presented in the preceding section, had its origins in SLA research during the 1970s. Studies have shown that during the interaction, the lack of comprehension on the listener's part prompts him/her to ask for clarification, repetition or confirmation, resulting in the speaker's adjustments of his/her language to make it more understandable. It has therefore been argued that negotiation of meaning provides learners with comprehensible input and thus facilitates L2 acquisition.

Procedural negotiation, which is often referred to as syllabus negotiation, is, as Breen and Littlejohn (2000) define, "the discussion between all members of the classroom to decide how learning and teaching are to be organised" (p. 1). As the purpose of the discussion is to reach agreement among the parties involved, the use of 'negotiation' here is in a sense similar to that in industrial or international politics (Bloor \& Bloor, 1988; Boomer et al., 1992; Breen \& Littlejohn, 2000). However, since "there should be no conflict between the goals of the parties, the teacher's aim being to achieve what is best for the students", classroom negotiation is "not a bargaining process [...] but a joint exploration of possibilities and targets, an exploration to which [the teacher and the students] bring different specialist knowledge" (Bloor \& Bloor, 1988: 63). It is this type of negotiation which evolved from the concern regarding how to make the teaching and learning process more communicative during the 1980s and which is also the focus of the present study.

2. Arguments for procedural negotiation

Subsequent are the chief reasons for implementing procedural negotiation in language teaching and learning.

a. Negotiation can make the teaching responsive to learners' needs.

Given learners' different experiences, expectations and preferences, any syllabus determined by the institution or the teacher prior to the encounter between the teacher and the learners proves inadequate (Nunan, 1988; Breen \& Littlejohn, 2000). Even when information about learners is collected in order to diagnose their needs, the discrepancy between the demands of the classroom and the prescribed syllabus cannot be satisfactorily bridged. The reason is the information collected is only objective or factual information such as age, occupation, language proficiency and educational background. Subjective information (attitudes, preferred methodology and learning-style preferences), which is more useful for the selection of content and methodology, can only be obtained once the teacher has met the students and a mutual relationship has been established between them. Therefore, any pre-determined syllabus which is based on information gathered in the initial collection is "superficially learner-centred" (Nunan, 1988: 24). Negotiated syllabus is, meanwhile, more relevant to learners' needs. Through ongoing dialogue, teacher and learners gradually discover the latter's affective needs, expectations and preferences (Nunan, 1988; Tudor, 1996). The subjective information obtained then helps to shape and refine the content, objectives and even the methodology, which include learning activities and materials, during the course of programme delivery, particularly in the initial stages (Nunan, 1988). The modified syllabus is therefore more responsive and learner-centred.

b. Negotiation can increase learners' motivation and involvement in learning

Negotiation helps generate learner interest and engagement in learning as it offers them the shared ownership of the course. In participating in decision-making via negotiation and consultation with teacher, learners play a more active 
role in the shaping of their learning program. This gives them a sense of ownership, which in turn leads to increasing involvement in the course (Brandes \& Ginnis, 1986; Bloor \& Bloor, 1988; Boomer et al., 1992). This engagement can be seen in learners' investment and commitment. Since "people tend to strive hardest for the things they wish to own, or to keep and enhance things they already own", learners will be intrinsically motivated to contribute to the construction and modification of the study program (Cook, 1992: 15). As Bloor \& Bloor (1988) believe, "negotiation inevitably recurs as the course proceeds, and, if the students want changes, they are likely to give voice in their views. This can motivate the students to continued involvement in the course" (p. 15). And because the educational program is what they have chosen, learning becomes more relevant, meaningful and intentional; learners will study harder and thus learn more and better.

c. Negotiation can foster learner autonomy

To start with, the negotiating process helps raise learners' awareness, a prerequisite for developing learner responsibility. As most learners enter a course with a vague idea about what they hope to acquire, any course designed to increase learners' responsibility must set out to help them have a clear understanding of their strengths and weaknesses and their expectations and preferences. Negotiation provides the context to develop such a critical selfawareness (Bloor \& Bloor; 1988; Nunan, 1988). Through the ongoing dialogue with teacher, learners are encouraged to reflect upon their prior knowledge, learning experiences, affective needs and preferences. Gradually, they come to understand and, more importantly, are able to articulate their needs and learning goals. Moreover, the sharing of perspectives and the joint selection of learning content and form helps learners become aware of the facilities available and the range of learning options as well as constraints in their learning context and hence able to understand the consequences of choices they make (Bloor \& Bloor; 1988; Nunan, 1988; Breen \& Littlejohn, 2000). These insights enable learners to begin to assume more control over their learning.

Additionally, negotiation facilitates a reformulation of the traditional roles in the classroom. Normally, it is the institution and the teacher who make decisions relative to learning content and form and learners are supposed to be passive "consumers" of language courses. In the process of negotiation and consultation, learners have an opportunity to contribute to the decision making by bringing their prior knowledge, learning experiences and attitudes and voicing their wants and preferences. The collaborative relationship established via ongoing dialogue and the teacher's appreciation and acknowledgement of their ideas help build and enhance learners' confidence and self-esteem, which, in turn, promotes their interest and motivation. They then willingly continue to get involved in the negotiating process in order to exploit the learning options available for their own benefit. Further, the sense of ownership, as mentioned earlier, motivates them to willingly take control of their own learning (Brandes \& Ginnis, 1986; Boomer et al., 1992).

Negotiation helps foster learner autonomy, which has been one of the major concerns in the profession since 1960s (Bloor \& Bloor, 1986; Boomer et al., 1992; Tudor, 1996; Breen \& Littlejohn, 2000). It is what Tudor (1996) calls learner empowerment, which is "the ultimate goal of a learner-centred approach to teaching" (p. 27). Learner empowerment "relates to learners' ability to assume an active and informed role in their language study and, ultimately, to pursue those of their life goals which pertain to language use and learning in self-directive manner" (ibid: 28). Breen and Littlejohn (2000) make it clear what it means to be autonomous in learning:

However, negotiation entails freedom within discipline. It does not mean 'anything goes'. Collaborative decisionmaking requires the constant balancing of an individual agenda with everyone else's. It also requires the constant balancing of particular goals, be they negotiable or not, with personal purposes and preferences for learning. In the classroom group, genuine autonomy has to be exercised in an interdependent way. (p. 22)

As a result of the involvement in the shared decision-making, learners become responsible members of the classroom community, who will later become "people who are self reliant and flexible in their working lives, socially responsible rather than merely self-seeking and collaborative rather than competitive in their dealings with other people"(ibid: 20).

d. Negotiation can enrich classroom discourse and the social and cultural resources of the classroom group

A major advantage of syllabus negotiation, or procedural negotiation, is that it provides the context for expanding and enhancing personal and, more importantly, interactive negotiation, which are essentially beneficial for the learning of a language. In discussing and reaching a consensus related to learning content and form, learners inevitably engage in the process of negotiating for meaning, which includes sharing, checking comprehension and clarifying meanings. Underlying this interactive negotiation is the mental process of interpreting and expressing meaning, namely personal negotiation. Breen and Littlejohn (2000: 10) have illustrated the relationship of "interactivity and entailment" of the three forms of negotiation as follows (Figure 1):

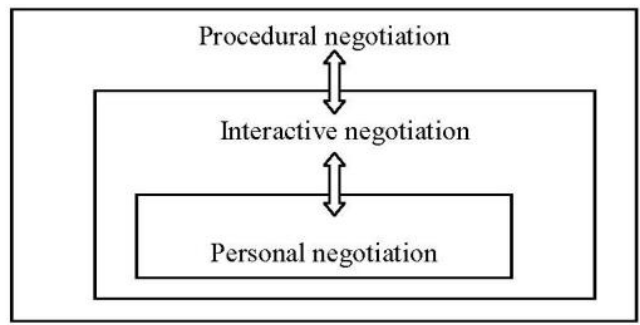

Figure 1: Relationship between three kinds of negotiation 
"Genuine communication" generated in the process of negotiating and consulting "diversifies the input, extends opportunities for learner output, and allows the exercise of judgements of appropriacy and accuracy in relation to the language made available for learning" (ibid: 26). Classroom discourse which is diverse and authentic therefore promotes the acquisition of the target language and hence improves learners' communicative capacities.

Another rewarding aspect of the collaborative process of shaping the learning programme is that it can generate diversified social and cultural resources. Breen and Littlejohn (2000) describe the classroom, "a microcosm of the wider society", as "multicultural in terms of the different voices and perspectives on the new language, on learning and on most things in the world" (p. 23). This multicultural feature is certainly apparent in a class of learners from different cultural backgrounds. Each member in the classroom community therefore contributes to the share decision-making by bringing their own prior knowledge, learning experiences, preferences and views on the teaching and learning process. This results in evolving differing ways of working, which, in turn, enrich their own repertory of learning strategies. What's more, the drawing on the multicultural resources of the classroom community can develop "an openness and flexibility in students' approaches to the learning" (ibid: 23).

It should be noted that the generation of diverse language, social and cultural resources is a beneficial part of classroom interaction that is natural or, in other words, unplanned by the institution or teacher in advance. This exemplifies what Boomer et al. (1992) call "incidental learning". As Onore (1992) notes, "unlike traditional curriculum, where it is assumed that what is learned is equivalent to what is taught, in negotiation it is acknowledged that a great deal of learning is incidental, unplanned, and even unconscious. But it is learning, nonetheless" (p.188).

\section{B. Tasks in Language Teaching and Learning}

\section{Task-based learning}

The recognition of the effectiveness of tasks as a stimulus to language learning comes from task-based learning (TBL), which evolved from CLT and rested on the findings in SLA research. The CLT movement arose from one significant innovation in the field of linguistics in the late twentieth century, i.e. the development of the notion of "communicative competence", as proposed by Hymes in contrast to Chomsky's "linguistic competence". In the early days of its evolvement, the advocates of CLT attempted to create a communicative syllabus which specified the notions and functions appropriate with the learners' communicative needs and a communicative approach that put an emphasis on language use in the classroom (Willis \& Willis, 2001). Subsequent research on CLT, however, raised considerable doubts as to its effectiveness in accommodating learners' needs and promoting communication (Carter \& Nunan, 2001, Kumaravadivelu, 2006). The communicative syllabus was "still a series of language patterns, albeit patterns linked to semantic and pragmatic values" and in the so-called communicative language classrooms, "there was still a powerful tendency to see the study of language form as prior to language use", with tasks being "used to assist 'free' production at the end of a controlled form-based teaching cycle" (Willis \& Willis, 2001, 174-5). Consequently, since the 1980s CLT has evolved in different directions and one important development is TBL.

TBL has its root in SLA research. Studies in the 1980s and 1990s denote that genuine interaction will engage learners' general cognitive processing capacities, which will result in the development of their language system. Therefore, in the classroom, "if we can provide learners with a series of tasks which involve both the comprehension and the production of language with a focus on meaning this will prompt language development" (Willis \& Willis, 2001 : 176). TBL then stresses the significance of language use and meaning-based tasks and views the learning process as one of learning through doing (Willis \& Willis, 1996; Nunan, 1999; Carter \& Nunan, 2001; Richards \& Renandya, 2002; Ellis, 2003).

2. Definition of 'task'

With the advent of TBL, task assumes a central role in syllabus design and methodology. There is, however, no agreement in relation to the definition of task in the language teaching literature. In his book in 2003, Ellis, after examining a number of definitions, combines almost all the main points regarding what a 'task' is in a comprehensive definition:

A task is a workplan that requires learners to process language pragmatically in order to achieve an outcome that can be evaluated in terms of whether the correct or appropriate propositional content has been conveyed. To this end, it requires them to give primary attention to meaning and to make use of their own linguistic resources, although the design of the task may predispose them to choose particular forms. A task is intended to result in language use that bears a resemblance, direct or indirect, to the way language is used in the real world. Like other language activities, a task can engage productive or receptive, and oral or written skills, and also various cognitive processes. (p. 16)

From his composite definition, 6 criterial features of a task can be identified:

1). A task is a workplan.

2). A task involves a primary focus on meaning.

3). A task involves real-world processes of language use.

4). A task can involve any of the four language skills.

5). A task engages cognitive processes.

6). A task has a clearly defined communicative outcome. (Ellis, 2003: 9-16)

According to Ellis, numbers 3, 6 and, particularly, 2 are important features of a task, whereas numbers 1, 4 and 5 can be found in all kinds of teaching materials, including exercises. 
3. Task components

A framework for describing a task is of great importance in analysing, classifying, selecting, adapting and designing tasks. However, as with the definition of tasks, there is no definite answer to the question of what a task consists of.

According to Wright (1987), there are two principal components in a task: 'input data' from materials, teachers or learners and 'instructional questions' which tell learners what they are going to do with the data (in Nunan, 1989; Ellis, 2003). Wright does not include 'objectives' or 'outcomes' in his framework since it is, according to him, impossible to predict the outcome(s) of a task. Learners' expectations about the nature of learning tasks and the way in which they perform the tasks will, as he argues, influence the dynamics of the classroom and the learning outcomes. There is thus a discrepancy between the actual outcome of a task and what the teacher expects learners to learn from it.

Ellis (2003) suggests a more complex framework with 5 components:

TABLE 1:

A FRAMEWORK FOR DESCRIBING TASKS (ELLIS, 2003: 21)

\begin{tabular}{|l|l|}
\hline Design feature & Description \\
\hline Goal & $\begin{array}{l}\text { The general purpose of the task, e.g. to practise the ability to describe objects concisely; to provide an opportunity for } \\
\text { the use of relative clause. }\end{array}$ \\
\hline Input & $\begin{array}{l}\text { The verbal or non-verbal information supplied by the task, e.g. pictures; a map; written text. } \\
\text { e.g. converging vs. diverging. }\end{array}$ \\
\hline Conditions & $\begin{array}{l}\text { The methodological procedures to be followed in performing the task, e.g. group vs. pair work; planning time vs. no } \\
\text { planning time. }\end{array}$ \\
\hline Procedures & $\begin{array}{l}\text { The 'product' that results from completing the task, e.g. a completed table; a route drawn in on a map; a list of } \\
\text { differences between two pictures. The predicted product can be 'open', i.e. allow for several possibilities, or 'closed', } \\
\text { i.e. allow for only one 'correct' solution. }\end{array}$ \\
\hline Process & The linguistic and cognitive processes the task is hypothesized to generate. \\
\hline
\end{tabular}

Ellis draws a distinction between the kind of input provided to learners and the way in which it is presented. The same input may, as he points out, be presented or used in different ways and likewise, different input in one way. Regarding the predicted outcomes, he argues that one of the important criterial features of tasks is clearly defined product outcomes. As for process outcomes, they can be predicted and, more importantly, "in language pedagogy, [...] tasks are devised with the expectation that they will generate specific process outcomes" (ibid: 20). Therefore, predicted outcomes must, according to him, be included in a framework for describing tasks.

In his interesting book in 1989, Nunan proposes a framework for analysing communicative tasks as follows:

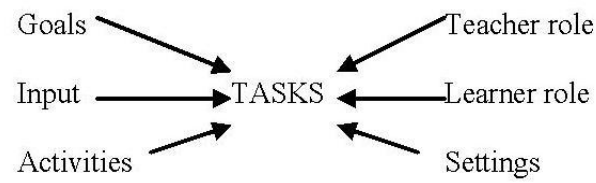

Figure 2: A framework for analysing communicative tasks (Nunan, 1989: 48)

As seen from Figure 2, Nunan shares Wright's point about the unpredictability of outcomes. Yet, he includes 'goals' as a task element, which he defines as "the vague general intentions behind any given learning task" (Nunan, 1989: 48). The goals of the tasks must coincide with the objectives of the broader curriculum. In addition, there is usually no oneto-one relationship between the goals and the tasks. In other words, a task may consist of a number of activities and thus have more than one goal.

As for input, a wide range of data sources around us can be exploited. Nunan raises the issue of authenticity. According to proponents of authentic materials, learners should be exposed to real-world texts in the classrooms so that they are prepared to cope with what they hear or read outside the classroom.

'Activities' refers to "what learners will actually do with the input which forms the point of departure for the learning task" (ibid: 59). They can be analysed according to the extent to which they mirror the kind of activities learners might do in the real world, whether they aim at 'skill getting' or 'skill using' and whether they focus on fluency or accuracy.

"'Role' refers to the part that learners and teachers are expected to play in carrying out learning tasks as well as the social and interactional relationships between the participants" (ibid: 79). Implicit in tasks are, therefore, assumptions regarding the control and power in the classrooms. For example, learners usually play a more active and powerful part in role-plays and problem solving tasks than in drills and the like. The roles of teachers and learners are closely related. In communicative approaches, for example, the learner is "an interactor and negotiator who is capable of giving as well as taking" while the teacher play the role of "facilitator", "participant", "observer" and "learner" (ibid: 80 \& 87). One important point concerning roles is the mismatch between learners' and teachers' role perceptions. Nunan suggests in such cases there be consultation and negotiation between teachers and learners.

"'Settings' refers to the classroom arrangements specified or implied in the task, and it also requires consideration of whether the task is to be carried out wholly or partly outside the classroom" (ibid: 91). This component is also of great 
importance in task selection and design as whether learners are going to work individually, in pairs or in groups and where the task is going to be done may influence the roles and relationships of the participants in the classroom.

Above are three frameworks selected from a number of proposals regarding task description. Each framework contributes to the difficult task of analysing learning tasks in their own way. Nunan's framework is particularly interesting since it points out the implicit assumptions of learner and teacher roles in tasks. More importantly, Nunan highlights the frequent discrepancy between teachers and learners' role perceptions and the need to involve learners in task selection and design.

4. Task types

A variety of task typologies can be found in the professional literature. Tasks can be categorized in terms of their real-world value (i.e. real-world versus pedagogic tasks), the kind of input data (e.g. map, pictures, stories), how the input is organised (i.e. split versus shared information tasks), whether interaction is required in order to achieve the outcome (i.e. reciprocal versus non-reciprocal), the kind of activity that learners are going to perform (e.g. role-plays, discussions, decision-making activities), the type of discourse they elicit (e.g. narrative, description, instructions), the type of cognitive activity involved (e.g. information-gap, reasoning-gap, opinion-gap tasks) and so on. Clearly, there is no consensus on the classification of tasks. Besides, most of the distinctions are continuous rather than dichotomous (Nunan, 1989; Ellis, 2003). Take the reciprocal/non-reciprocal distinction, for example. Some tasks are obviously reciprocal (e.g. speaking tasks in which participants have to interact to achieve the outcome); some are non-reciprocal (e.g. listening tasks in which learners cannot interrupt); and there are some which are somewhere in the middle rather than at one end of the continuum (e.g. an interactive lecture in which students have the opportunity to interrupt the lecturer). What's more, there are many tasks which contain a number of subtasks. 'Projects', for instance, often involve different types of tasks such as comparing, problem-solving, and sharing personal experiences (Ellis, 2003). An agreed classification of tasks therefore continues to elude the profession.

Another question related to task types that remains unanswered is what kinds of tasks promote language acquisition. Research into task types has revealed a lot of useful findings. For example, small group work encouraged learners to use a greater variety of language functions than whole-class activities; two-way tasks (i.e. tasks in which the information to be exchanged is split between two or more participants) produce more interaction modifications than one-way tasks; tasks of the required information type (i.e. tasks that require all the participants to exchange information) generate more negotiation of meaning than tasks of the optional information type (Nunan, 1989; Ellis, 2003). Although these findings are of great value for syllabus designers and teachers, much has remained to be done in order to arrive at an adequate answer to the question. It is because there are a lot of factors that may influence the effects of tasks on learning such as the teaching cycle, the topic or content matter, the learners' characteristics and expectations, the situational factors and so on. Take, the learner and context factors, for example. Whereas a lot of research has proved that information-gap tasks help to promote acquisition, Prabhu, basing on his teaching experience in high schools in southern India, advocated reasoning-gap tasks (Ellis, 2003). Ellis (2003) therefore points out that "the type of task that works best may depend on the contingencies of individual teaching contexts" (p. 214).

5. Tasks and syllabus negotiation

As already noted in the discussion on task components, there is a connection between learning tasks and the redistribution of the roles of the participants in the classroom. This has a significant implication for the implementation of syllabus negotiation: as a key unit of the syllabus, tasks can be used as the vehicle for encouraging learners to make choices regarding the learning content and form and play a more active role in their own learning. By involving learners in selecting, adapting and creating tasks, "one opens to the student the possibility of planning and monitoring learning one breaks down the hierarchic barriers as it were" (Nunan, 1989: 20). Besides, negotiating tasks is a practical choice in situations where there exist such constraints as an externally determined syllabus, time constraints and large class size. As Breen and Littlejohn (2000) suggest, "making negotiation available at the higher levels of the pyramid (for example at the level of how students are to work on a chosen task) can offer initial experience for both teachers and students in managing shared decision-making, without jeopardising the structure of the course as a whole" (p. 287).

\section{RESEARCH METHODOLOGY}

\section{A. Participants}

77 first-year students (from among a population of 241 first-year students), 58 females and 19 males, from the two classes of practically analogous English proficiency level (predicated on the students' scores from the pretest) at the Faculty of English Linguistics of Hung Vuong University were invited to participate in the study. The average age was 19.26 years ranging from 18 to 24 years old.

One first-year class (2010B) was treated as the experimental group (EG), and the other (2010E) as the control group (CG). The students in the experimental group were immersed in the selection of learning content and form through negotiating tasks with the teacher whereas the students in the control group were taught according to the syllabus imposed by the Faculty of English Linguistics.

\section{B. Instrumentation and Procedure}


Pretest and posttest were employed as instruments to measure students' English proficiency level. The initial English proficiency level of the whole population of first-year students was investigated by the pretest, from which scores contributed to the choice of the experimental group and control group of virtually similar English competence level.

Upon the arrival of the fifteenth week, the students in both experimental group and control group took the post-test, which sought to assess the impact of task negotiation on the students' English competence.

The main purpose of the questionnaire survey is to learn about the students' evaluation of the course under study. The students' comments and opinions, though subjective, can yield significant insights into the impacts of task negotiation on the English teaching and learning. The questionnaires were handed out on the day the students took the posttest. The numbers of completed questionnaires collected were 35 in the experimental group and 37 in the control group.

\section{FINDINGS AND DISCUSSION}

\section{A. Impact of Task Negotiation Practice on Learners'English Competence}

As regards the results of the posttest, the findings from an independent samples t-test demonstrated that Class 2010B (EG) mean score $(\mathrm{M}=6.5366)$ was significantly higher (sig. 2-tailed value $\mathrm{p}=.024<.05)$ than Class $2010 \mathrm{E}(\mathrm{CG})$ mean score $(M=5.2073)$, implying the English competence of the students of the EG improved at a higher level than that of the students of the CG.

TABLE 2:

THE OUTPUT PRODUCED BY THE T-TEST ANALYSIS OF THE POST-TEST SCORES

\begin{tabular}{|l|l|l|l|l|l|l|l|}
\hline & \multicolumn{6}{|l|}{$\begin{array}{l}\text { Levene's Test for Equality } \\
\text { of Variances }\end{array}$} & \multicolumn{5}{l|}{ t-test for Equality of Means } \\
\cline { 2 - 8 } & $\mathrm{F}$ & Sig. & $\mathrm{t}$ & $\mathrm{df}$ & Sig. (2-tailed) & $\begin{array}{l}\text { Mean } \\
\text { Difference }\end{array}$ & $\begin{array}{l}\text { Std. Error } \\
\text { Difference }\end{array}$ \\
\hline $\begin{array}{l}\text { Equal variances assumed } \\
\text { Equal variances not } \\
\text { assumed }\end{array}$ & .044 & .024 & 1.375 & 70 & .174 & .3404 & .24760 \\
\hline
\end{tabular}

\section{B. The Students' Reactions towards the Course through Questionnaire Survey}

a. Students' evaluation of the tasks done in the course

1. Question 1 is concerned with the students' opinions about how interesting the tasks done in the course were. The results shown in Table 3 reveal a noticeable difference in the evaluation of the two groups. While almost all the students in the experimental group (94.3\%) found the tasks very interesting, just more than half of the students in the control group did (56.7\%). Particularly, more than twice as many experimental students chose the response with the highest intensity in the scale compared with the control students. On the other hand, $18.9 \%$ of the control students thought the tasks were boring.

TABLE 3:

\begin{tabular}{|l|l|l|l|l|}
\multirow{2}{*}{ STUDENTS' OPINIONS OF HOW INTERESTING THE TASKS WERE } \\
\cline { 2 - 5 } Responses & Experimental group & \multicolumn{2}{|l|}{ Control group } \\
\cline { 2 - 5 } & Frequency & Percent & Frequency & Percent \\
\hline 1-not at all & 0 & 0.0 & 0 & 0.0 \\
2 & 0 & 0.0 & 7 & 18.9 \\
3 - somewhat & 2 & 5.7 & 9 & 24.3 \\
4 & 23 & 65.7 & 16 & 43.2 \\
5 - extremely & 10 & 28.6 & 5 & 13.5 \\
\hline Total & 35 & 100.0 & 37 & 100.0 \\
\hline
\end{tabular}

2. Similar findings can be drawn from the responses to Question 2, dealing with the students' perceptions of the usefulness of the tasks (see Table 4). A vast majority of the experimental students (94.2\%) agreed that the tasks in the course were very useful whereas less than three-thirds of the control students $(62.1 \%)$ did. Also, the number of students in the experimental group selecting the highest level is almost double that in the control group. And there were a few control students $(13.5 \%)$ giving unfavourable responses to this question. 
TABLE 4:

STUDENTS' OPINIONS OF THE USEFULNESS OF THE TASKS

\begin{tabular}{|l|l|l|l|l|}
\hline \multirow{2}{*}{ Responses } & \multicolumn{2}{|l|}{ Experimental group } & \multicolumn{2}{l|}{ Control group } \\
\cline { 2 - 5 } & Frequency & Percent & Frequency & Percent \\
\hline 1 - not at all & 0 & 0.0 & 0 & 0.0 \\
2 & 0 & 0.0 & 5 & 13.5 \\
3 - somewhat & 2 & 5.7 & 9 & 24.3 \\
4 & 20 & 57.1 & 16 & 43.2 \\
5 - extremely & 13 & 37.1 & 7 & 18.9 \\
\hline Total & 35 & 100.0 & 37 & 100.0 \\
\hline
\end{tabular}

3. However, regarding the difficulty level of the tasks, the figures are broadly similar across the groups (see Table 5). More than half of the students in both groups agreed that generally the level of the tasks was just right (68.6\% in the experimental group and $62.2 \%$ in the control group).

TABLE 5:

STUDENTS' OPINIONS OF THE DIFFICULTY LEVEL OF THE TASKS

\begin{tabular}{|l|l|l|l|l|}
\hline \multirow{2}{*}{ Responses } & \multicolumn{2}{|l|}{ Experimental group } & \multicolumn{2}{l|}{ Control group } \\
\cline { 2 - 5 } & Frequency & Percent & Frequency & Percent \\
\hline 1 - very easy & 0 & 0.0 & 0 & 0.0 \\
2 & 2 & 5.7 & 4 & 10.8 \\
3 - just right & 24 & 68.6 & 23 & 62.2 \\
4 & 6 & 17.1 & 8 & 21.6 \\
$5-$ very difficult & 3 & 8.6 & 2 & 5.4 \\
\hline Total & 35 & 100.0 & 37 & 100.0 \\
\hline
\end{tabular}

4. In response to Question 4, a large proportion of the experimental group claimed that they frequently felt involved in the tasks (51.4\% usually and $22.9 \%$ always) while just nearly half of the control group did $(43.2 \%$ usually and only $5.4 \%$ always). $43.2 \%$ and $8.1 \%$ of the control students chose "sometimes" and "seldom" respectively, compared to only $25.7 \%$ and $0.0 \%$ respectively of the experimental ones (see Table 6).

TABLE 6:

STUDENTS' INVOLVEMENT IN THE TASKS

\begin{tabular}{|l|l|l|l|l|}
\hline \multirow{2}{*}{ Responses } & \multicolumn{2}{|l|}{ Experimental group } & \multicolumn{2}{l|}{ Control group } \\
\cline { 2 - 5 } & Frequency & Percent & Frequency & Percent \\
\hline $1-$ never & 0 & 0.0 & 0 & 0.0 \\
2 & 0 & 0.0 & 3 & 8.1 \\
3 - sometimes & 9 & 25.7 & 16 & 43.2 \\
4 & 18 & 51.4 & 16 & 43.2 \\
5 - always & 8 & 22.9 & 2 & 5.4 \\
\hline Total & 35 & 100.0 & 37 & 100.0 \\
\hline
\end{tabular}

5. Results of the four previous questions reveal that generally the responses of the experimental group were more positive than those of the control group. This finding is confirmed by the information attained from Question 5, concerning the students' overall assessment of the tasks. The experimental students largely agreed that the tasks were good, with more than a third rating them as "very good". By comparison, just nearly two-thirds of the control group selected positive responses, with only $8.1 \%$ choosing the highest level. There was a small proportion of the control students $(8.1 \%)$ thinking the tasks were generally not good (see Table 7 ).

TABLE 7:

STUDENTS' OVERALL EVALUATION OF THE TASKS

\begin{tabular}{|l|l|l|l|l|}
\hline \multirow{2}{*}{ Responses } & \multicolumn{2}{|l|}{ Experimental group } & \multicolumn{2}{l|}{ Control group } \\
\cline { 2 - 5 } & Frequency & Percent & Frequency & Percent \\
\hline $1-$ very bad & 0 & 0.0 & 0 & 0.0 \\
2 & 0 & 0.0 & 3 & 8.1 \\
3 - average & 5 & 14.3 & 11 & 29.7 \\
4 & 19 & 54.3 & 20 & 54.1 \\
$5-$ very good & 11 & 31.4 & 3 & 8.1 \\
\hline Total & 35 & 100.0 & 37 & 100.0 \\
\hline
\end{tabular}


b. Students' self-assessment

1. Question 6 asked the students to evaluate their interaction with their classmates during the course. Whereas the whole experimental group gave positive responses to this question, not all the control students $(86.5 \%)$ did. The number of experimental students choosing level 4, i.e. "quite a lot", is almost double that of the control group and the difference was even greater in the response with the highest intensity as displayed in Table 8.

TABLE 8:

STUDENT-STUDENT INTERACTION

\begin{tabular}{|l|l|l|l|l|}
\hline \multirow{2}{*}{ Responses } & \multicolumn{2}{|l|}{ Experimental group } & \multicolumn{2}{l|}{ Control group } \\
\cline { 2 - 5 } & Frequency & Percent & Frequency & Percent \\
\hline 1- very little & 0 & 0.0 & 0 & 0.0 \\
2 & 0 & 0.0 & 5 & 13.5 \\
3 - normally & 19 & 54.3 & 24 & 64.9 \\
4 & 11 & 31.4 & 6 & 16.2 \\
$5-$ a great deal & 5 & 14.3 & 2 & 5.4 \\
\hline Total & 35 & 100.0 & 37 & 100.0 \\
\hline
\end{tabular}

2. In terms of interaction between teacher and students, the results are also more positive in the experimental group. Over one-third of the experimental students questioned (31.4\%) felt that they talked a lot with the teacher during the course compared with only $16.2 \%$ of the control group. Generally, the experimental group's percentage for the favourable options (71.4\%) was significantly higher (see Table 9).

TABLE 9:

TEACHER-STUDENT INTERACTION

\begin{tabular}{|l|l|l|l|l|}
\hline \multirow{2}{*}{ Responses } & \multicolumn{2}{l|}{ Experimental group } & \multicolumn{2}{l|}{ Control group } \\
\cline { 2 - 5 } & Frequency & Percent & Frequency & Percent \\
\hline 1 - very little & 0 & 0.0 & 2 & 5.4 \\
2 & 10 & 28.6 & 13 & 35.1 \\
3 - normally & 14 & 40.0 & 16 & 43.2 \\
4 & 9 & 25.7 & 5 & 13.5 \\
$5-$ a great deal & 2 & 5.7 & 1 & 2.7 \\
\hline Total & 35 & 100.0 & 37 & 100.0 \\
\hline
\end{tabular}

3. The next question also reveals that a greater number of experimental students contributed to the lessons by answering questions of the teacher and fellow students or offering their own ideas. In particular, as shown in Table 10, $65.7 \%$ of the experimental students claimed that they sometimes or frequently participated in the lessons whereas just nearly half of the control group (45.9\%) did.

TABLE 10:

STUDENTS' CONTRIBUTION TO THE CLASSES

\begin{tabular}{|l|l|l|l|l|}
\hline \multirow{2}{*}{ Responses } & \multicolumn{2}{|c|}{ Experimental group } & \multicolumn{2}{l|}{ Control group } \\
\cline { 2 - 5 } & Frequency & Percent & Frequency & Percent \\
\hline $1-$ never & 2 & 5.7 & 10 & 27.0 \\
2 & 10 & 28.6 & 10 & 27.0 \\
3 - sometimes & 16 & 45.7 & 12 & 32.4 \\
4 & 5 & 14.3 & 4 & 10.8 \\
$5-$ very frequently & 2 & 5.7 & 1 & 2.7 \\
\hline Total & 35 & 100.0 & 37 & 100.0 \\
\hline
\end{tabular}

4. Question 9, which consisted of 7 sub-questions, enquires as to what the students learned from the course. In each sub-question, there are five options for them to choose: not at all, almost nothing, a little, to some extent, a lot. Given the limited amount of time allocated for this course, the third choice is regarded as a positive response to the question. The results are represented in Figures 3 and 4. 


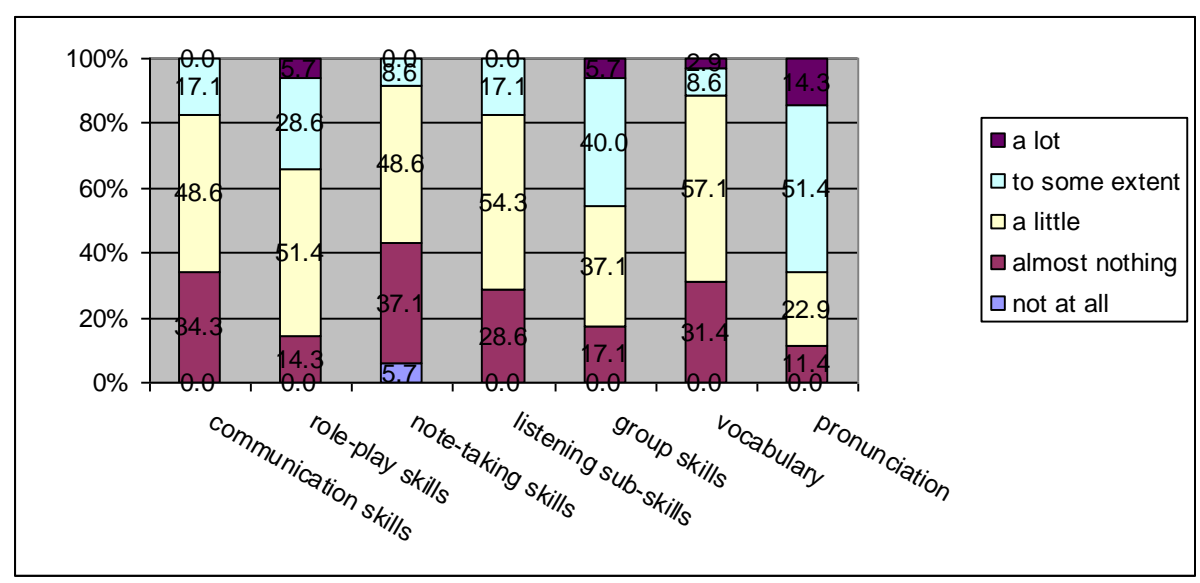

Figure 3: Experimental students' perceptions of what they learned

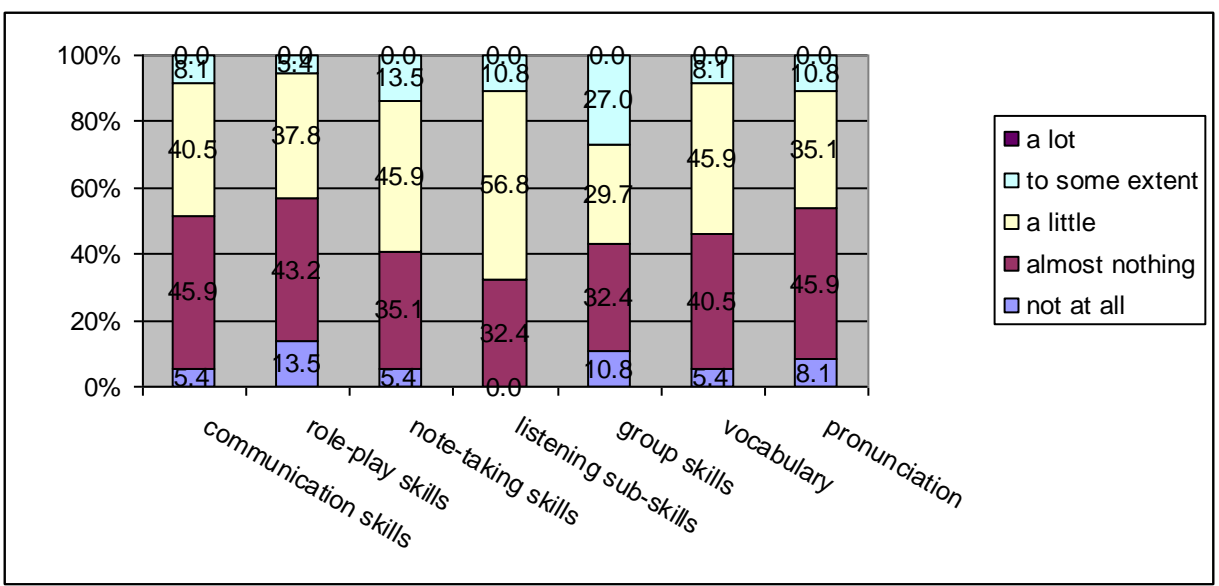

Figure 4: Control students' perceptions of what they learned

As shown by the first bars of the two figures, the number of favourable responses of the experimental group in subquestion 1 was much greater. $65.7 \%$ of the experimental students reported to have learnt communication skills as compared to $48.6 \%$ of the control students.

In response to part 2 of the question, more than three-quarters of the experimental students $(85.7 \%)$ claimed to have learnt something about role-play skills from the course. The proportion of the control students choosing positive alternatives was much smaller: $43.2 \%$. Particularly, $28.6 \%$ and $5.7 \%$ of the experimental students selected "4" and "5" respectively (which are the two highest levels), compared to only $5.4 \%$ and $0.0 \%$ respectively in the control group.

In the third sub-question, which is concerned with note-taking skills, the results are, however, fairly similar across the two groups: $57.2 \%$ of the experimental group and 59.4\% of the control group gave positive responses.

As regards listening sub-skills, there is also not much difference in the responses of the two groups. $71.4 \%$ of the experimental students and $67.6 \%$ of the control students claimed that they had learnt some listening sub-skills from the course.

On the other hand, there is some variation in the results for learning strategies, i.e. group skills. The experimental students selecting positive responses outnumbered the control students. Specifically, in the experimental group, $37.1 \%$ of the students thought they learnt a little about group skills, $40.0 \%$ to a fair degree and $5.7 \%$ a lot. By comparison, the corresponding figures of the control group are $29.7 \%, 27.0 \%$ and $0.0 \%$.

The fifth sub-question, which deals with vocabulary, also produced more favourable responses from the experimental group. $68.6 \%$ of the experimental students thought they had learnt some vocabulary from the course as compared with $54.0 \%$ of the control group.

The difference is particularly marked in the last section, i.e. pronunciation. Almost twice as many experimental students $(88.6 \%)$ thought they had learned how to pronounce from the course as the control students $(45.9 \%)$. Moreover the numbers for the two highest levels in the experimental group are remarkable: $51.4 \%$ for "to some extent" and $14.3 \%$ for "a lot".

On the whole, the results of Question 9 suggested that the experimental group seemed to gain more from the course than the control group.

5. Question 10 is interested in whether the students felt more self-confident after finishing the course. In response to this question (see Table 11), approximately three-quarters of the experimental group (74.3\%) claimed to be more 
confident, whereas nearly two-thirds of the control group (64.8\%) did. Almost twice as many experimental students selecting " 4 " and " 5 " as control students.

TABLE 11:

STUDENTS' ASSESSMENT OF THEIR INCREASED SELF-CONFIDENCE

\begin{tabular}{|l|l|l|l|l|}
\hline \multirow{2}{*}{ Responses } & \multicolumn{2}{|l|}{ Experimental group } & \multicolumn{2}{l|}{ Control group } \\
\cline { 2 - 5 } & Frequency & Percent & Frequency & Percent \\
\hline 1 - not at all & 3 & 8.6 & 6 & 16.2 \\
2 & 6 & 17.1 & 7 & 18.9 \\
$3-$ a little & 14 & 40.0 & 17 & 45.9 \\
4 & 11 & 31.4 & 7 & 18.9 \\
$5-$ a lot & 1 & 2.9 & 0 & 0.0 \\
\hline Total & 35 & 100.0 & 37 & 100.0 \\
\hline
\end{tabular}

6. Similarly, as displayed in Table 12, the figure of the experimental students who perceived some progress in their independence in studying English is higher than that of the control students ( $74.2 \%$ and $62.1 \%$ respectively). And it was noticeable that the number of responses with the two highest levels in the control group represented less than half that in the experimental group $(16.2 \%$ and $37.1 \%$ respectively).

TABLE 12:

STUDENTS’ ASSESSMENT OF THEIR PROGRESS IN INDEPENDENCE IN ENGLISH LEARNING

\begin{tabular}{|l|l|l|l|l|}
\hline \multirow{2}{*}{ Responses } & \multicolumn{2}{|l|}{ Experimental group } & \multicolumn{2}{l|}{ Control group } \\
\cline { 2 - 5 } & Frequency & Percent & Frequency & Percent \\
\hline $1-$ not at all & 1 & 2.9 & 5 & 13.5 \\
2 & 8 & 22.9 & 9 & 24.3 \\
$3-$ a little & 13 & 37.1 & 17 & 45.9 \\
4 & 11 & 31.4 & 6 & 16.2 \\
$5-$ a lot & 2 & 5.7 & 0 & 0.0 \\
\hline Total & 35 & 100.0 & 37 & 100.0 \\
\hline
\end{tabular}

7. Interestingly, as shown in Table 13 , the vast majority of both groups gave positive responses to question 12 , dealing with their increased interest in English learning. However, the number of the experimental students who felt that they liked studying English a lot better after finishing the course (77.2\%) is much greater (Although the figure of the control students choosing the response with the highest intensity is a bit higher, all things considered, it is not very important).

TABLE 13:

STUDENTS' ASSESSMENT OF THEIR INCREASED INTEREST IN STUDYING
\begin{tabular}{|l|l|l|l|l|}
\hline \multirow{2}{*}{ Responses } & Experimental group & \multicolumn{2}{l|}{ Control group } \\
\cline { 2 - 6 } & Frequency & Percent & Frequency & Percent \\
\hline $1-$ not at all & 0 & 0.0 & 1 & 2.7 \\
2 & 1 & 2.9 & 3 & 8.1 \\
$3-$ a little & 7 & 20.0 & 18 & 48.6 \\
4 & 22 & 62.9 & 8 & 21.6 \\
$5-$ a lot & 5 & 14.3 & 7 & 18.9 \\
\hline Total & 35 & 100.0 & 37 & 100.0 \\
\hline
\end{tabular}

c. Students' overall evaluation of the course

1. Question 13 relates to the number of tasks done in the course. As displayed in Table 14, a substantial majority of the experimental group agreed that there were enough tasks to do, while just over half of the control group was satisfied with the number of tasks. In addition, $20 \%$ of the experimental students thought that there were too many tasks, whereas $32.4 \%$ of the control students wanted to have more tasks. In general, the results of the experimental group are more positive than those of the control group. 
TABLE 14:

STUDENTS' OPINIONS OF WHETHER THERE WERE ENOUGH TASKS
\begin{tabular}{|l|l|l|l|l|}
\hline \multirow{2}{*}{ Responses } & \multicolumn{2}{|l|}{ Experimental group } & \multicolumn{2}{l|}{ Control group } \\
\cline { 2 - 5 } & Frequency & Percent & Frequency & Percent \\
\hline 1 - very few & 0 & 0.0 & 1 & 2.7 \\
2 & 0 & 0.0 & 11 & 29.7 \\
3 - sufficient & 28 & 80.0 & 22 & 59.5 \\
4 & 6 & 17.1 & 3 & 8.1 \\
5 - too many & 1 & 2.9 & 0 & 0.0 \\
\hline Total & 35 & 100.0 & 37 & 100.0 \\
\hline
\end{tabular}

2. The responses to the next question show the experimental group's higher rating as to the effectiveness of the course in enhancing their communicative competence. Almost all of the experimental students thought the course improved their communicative ability, whereas approximately three-quarters of the control group did. Significantly, over half of the students in the experimental group reported to have good progress, more than twice as many as in the control group (see Table 15).

TABLE 15:

STUDENTS' ASSESSMENT OF THE EFFECTIVENESS OF THE COURSE IN IMPROVING THEIR COMMUNICATIVE COMPETENCE

\begin{tabular}{|l|l|l|l|l|}
\hline \multirow{2}{*}{ Responses } & \multicolumn{2}{|l|}{ Experimental group } & \multicolumn{2}{l|}{ Control group } \\
\cline { 2 - 5 } & Frequency & Percent & Frequency & Percent \\
\hline $1-$ not at all & 0 & 0.0 & 0 & 0.0 \\
2 & 2 & 5.7 & 8 & 21.6 \\
$3-$ a little & 13 & 37.1 & 20 & 54.1 \\
4 & 20 & 57.1 & 9 & 24.3 \\
$5-$ a lot & 0 & 0.0 & 0 & 0.0 \\
\hline Total & 35 & 100.0 & 37 & 100.0 \\
\hline
\end{tabular}

3. The last close-ended question is concerned with the students' satisfaction over the way of teaching and learning in the course. The results indicated in Table 16 suggest that generally both groups were pleased with the way they were taught. Nevertheless, a few control students (10.8\%) showed their unhappiness over the mode of working in the course. In addition, the number of students who were quite satisfied represented less than half that in the experimental group.

TABLE 16:

STUDENTS' SATISFACTION WITH THE WAY OF WORKING

\begin{tabular}{|c|c|c|c|c|}
\hline \multirow{2}{*}{ Level } & \multicolumn{2}{|c|}{ Experimental group } & \multicolumn{2}{|c|}{ Control group } \\
\hline & Frequency & Percent & Frequency & Percent \\
\hline $1-$ not at all & 0 & 0.0 & 0 & 0.0 \\
\hline 2 & 0 & 0.0 & 4 & 10.8 \\
\hline 3 - somewhat & 2 & 5.7 & 16 & 43.2 \\
\hline 4 & 27 & 77.1 & 14 & 37.8 \\
\hline 5 - extremely & 6 & 17.1 & 2 & 5.4 \\
\hline Missing values & 0 & 0.0 & 1 & 2.7 \\
\hline Total & 35 & 100.0 & 37 & 100.0 \\
\hline
\end{tabular}

In a nutshell, the results obtained by means of the questionnaire survey suggest that task negotiation worked well in the course. The positive impacts of the approach can be seen in the experimental students' higher ratings as to the tasks done in the course, higher sense of achievement and progress and greater satisfaction with the mode of working.

\section{CONCLUSION}

The findings obtained through the data are sufficient to conclude that the approach in question worked well in the context of the study, which answers the research questions: task negotiation can be a viable approach in EFL classes at Hung Vuong University.

In addition to the conclusion concerning the effect of negotiation on the students' communicative competence as compared to that of the traditional teacher-led mode of working was drawn from the posttest scores, the more positive results attained through the experimental students' responses in the questionnaire indicate the effectiveness of the approach in question: it generated the students' motivation and involvement, promoted their learning initiative, enhanced their sense of progress, and facilitated group cohesion. Considering these positive impacts, classroom 
negotiation holds great promise for helping students improve their communicative competence. Moreover, the students' acceptance of the approach, which was reflected through their responses in the questionnaire, helps justify its productivity and workability. Overall the findings attest to the power of shared decision-making as a classroom practice in EFL classes. Besides the wide range of benefits, the results disclose some factors causing difficulties for participants in the negotiating process, including time constraints, large class size, student diversity, prior learning experiences. Nevertheless, difficulties such as these found in the study are, in fact, evident in almost all educational situations and therefore a realistic part of the negotiating process (Breen \& Littlejohn, 2000). On the whole, the negotiated work undertaken in the study can be considered successful, which proves the feasibility of procedural negotiation as an approach to language teaching in the Vietnamese context in general and at Hung Vuong University in particular.

\section{REFERENCES}

[1] Bloor, M. \& Bloor, T. (1988). Syllabus negotiation: the basis for learner autonomy. In A. Brookes \& P. Grundy (Eds.), Individualisation and autonomy in language learning (pp. 62-74). London: Modern English Publications \& the British Council.

[2] Boomer, G., Lester, N., Onore, C., \& Cook, J. (1992). Negotiating the curriculum: educating for the $21^{\text {st }}$ century. London: The Falmer Press.

[3] Brandes, D. \& Ginnis, P. (1986). A guide to student-centred learning. Herts: Simon \& Schuster Education.

[4] Breen, M.P. (2001). Syllabus design. In R. Carter \& D. Nunan (Eds.), The Cambridge guide to teaching English to speakers of other languages (pp. 151 - 159). Cambridge: CUP.

[5] Breen, M.P., \& Littlejohn, A. (2000). Classroom decision-making: negotiation and process syllabuses in practice. Cambridge: CUP.

[6] Carter, R. \& Nunan, D. (2001). The Cambridge guide to teaching English to speakers of other languages. Cambridge: CUP.

[7] Cook, J. (1992). Negotiating the curriculum: Programming for learning. In G. Boomer, N. Lester, C. Onore, \& J. Cook (Eds.), Negotiating the curriculum: educating for the $21^{\text {st }}$ century (pp. 15-31). London: The Falmer Press.

[8] Ellis, R. (2003). Task-based language learning and teaching. Oxford: OUP.

[9] Huang, J. (2006). Fostering learner autonomy within constraints: Negotiation and mediation in an atmosphere of collegiality. Prospect: An Australian Journal of TESOL, 21(3), 38-57.

[10] Kumaravadivelu, B. (2006). TESOL methods: Changing tracks, challenging trends. TESOL Quarterly, 40(1), 59-81.

[11] Nunan, D. (1988). The learner-centred curriculum. Cambridge: CUP.

[12] Nunan, D. (1989). Designing tasks for the communicative classroom. Cambridge: CUP.

[13] Nunan, D. (1992). Collaborative language learning and teaching. Cambridge: CUP.

[14] Nunan, D. (1999). Second language teaching and learning. Boston: Heinle \& Heinle Publishers.

[15] Onore, C.S. (1992). Negotiation, language, and inquiry: Building knowledge collaboratively in the classroom. In G. Boomer, N. Lester, C. Onore, \& J. Cook (Eds.), Negotiating the curriculum: educating for the $21^{\text {st }}$ century (pp. 181-193). London: The Falmer Press.

[16] Richards, J.C., \& Renandya, W.A. (Eds.). (2002). Methodology in language teaching: An anthology of current practice. Cambridge: CUP.

[17] Tudor, I. (1996). Learner-centeredness as language education. Cambridge: CUP.

[18] Willis, D. \& Willis, J. (2001). Task-based language learning. In R. Carter \& D. Nunan (Eds.). The Cambridge guide to teaching English to speakers of other languages (pp. 173-178). Cambridge: CUP.

[19] Willis, J. \& Willis, D. (Eds.) (1996). Challenge and change in language teaching. MacMillan Heinemann English Language Teaching.

[20] Wright, T. (1987). Instructional task and discoursal outcome in the L2 classroom. In C. Candlin \& D. Murphy (Eds.). Language learning tasks. Englewood Cliffs NJ: Prentice-Hall.

Luu Trong Tuan is currently an EFL teacher at National University of Ho Chi Minh City. He received his M.TESOL from Victoria University, Australia in 2004. Besides his focus on TESOL, his recent publications such as Language Transfer is Cultural Transfer between Communities, Social Sciences Review, No. 11, 2004, pp. 60-63; and Principles for Scientific Translation, Social Sciences Review, No. 8, 2004, pp. 63-67; and Building Vietnamese Medical Terminology via Language Contact, Australian Journal of Linguistics, Vol. 29, No. 3, September 2009, pp. 315-336 show his interest in language contact and translation areas. 